\title{
Ultra-radical surgery compared to standard surgical treatment for women with advanced ovarian cancer: a cost-effectiveness analysis
}

\author{
Giovanna Bettoli ${ }^{1}$, Andrew Phillips ${ }^{2}$, Sudha Sundar ${ }^{3}$, Carole Cummins ${ }^{4}$, and Anish Bali ${ }^{2}$ \\ ${ }^{1}$ University of Nottingham School of Medicine \\ ${ }^{2}$ Royal Derby Hospital \\ ${ }^{3}$ University of Birmingham Institute of Cancer and Genomic Sciences \\ ${ }^{4}$ University of Birmingham Institute of Applied Health Research
}

November 23, 2020

\begin{abstract}
Objective To compare current surgical practice for women with AOC to ultra-radical surgery; to assess whether the new approach would be cost-effective under NICE guidelines of approximately £20,000/QALY. Design Cost-effectiveness analysis. Setting NHS, using data from a variety of sources. Population Patients with advanced ovarian cancer (FIGO stages IIIC-IV). Methods A decision analytic model (microsimulation model) was built to examine the Objective; deterministic and probabilistic sensitivity analyses were used to test the susceptibilities of the baseline model and its assumptions. Main Outcome Measures ICER (incremental cost-effectiveness ratio). Results The standard model yielded an ICER of $£ 5325.06$; this is in spite of an associated overall decrease in utility due to predicted increase in surgical mortality. The parameters with the most significant impact on the ICER are the cost of ultra-radical surgery, the utility associated with progression-free survival, and the probability of death from ultra-radical surgery. Conclusions Ultra-radical surgery is cost-effective under NICE willingness-to-pay thresholds of $£ 20000$; the costs of ultra-radical surgery are bound to decrease as centres specialise further, and its effectiveness is also likely due to increase with development of newer techniques and more surgical training.
\end{abstract}

\section{Hosted file}

Cost-effectiveness of ultra-radical surgery - Main text and Table 1.pdf available at https: //authorea.com/users/378188/articles/494726-ultra-radical-surgery-compared-to-standardsurgical-treatment-for-women-with-advanced-ovarian-cancer-a-cost-effectiveness-analysis

\section{Hosted file}

Cost-effectiveness of ultra-radical surgery - Figure 1.pdf available at https://authorea. com/users/378188/articles/494726-ultra-radical-surgery-compared-to-standard-surgicaltreatment-for-women-with-advanced-ovarian-cancer-a-cost-effectiveness-analysis

\section{Hosted file}

Cost-effectiveness of ultra-radical surgery - Figure 2.pdf available at https://authorea. com/users/378188/articles/494726-ultra-radical-surgery-compared-to-standard-surgicaltreatment-for-women-with-advanced-ovarian-cancer-a-cost-effectiveness-analysis

\section{Hosted file}

Cost-effectiveness of ultra-radical surgery - Figure 3.pdf available at https://authorea. com/users/378188/articles/494726-ultra-radical-surgery-compared-to-standard-surgicaltreatment-for-women-with-advanced-ovarian-cancer-a-cost-effectiveness-analysis 